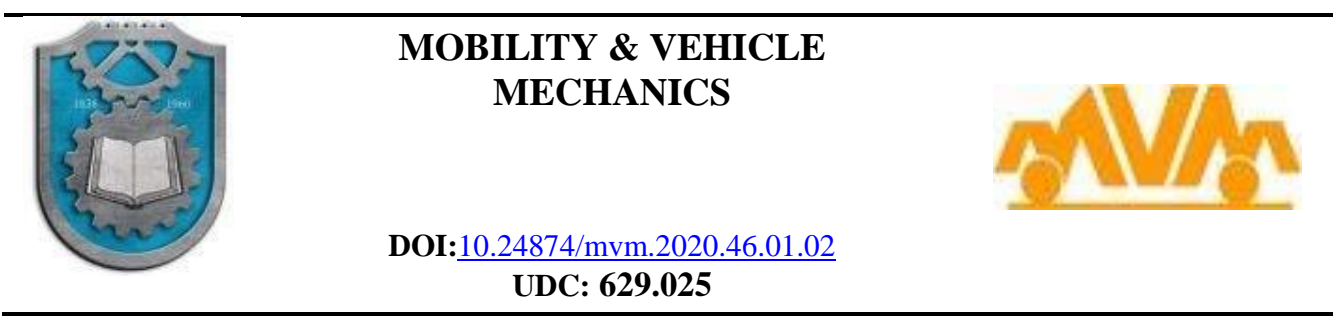

\title{
ON THE DESIGN OF THE STEERING AND FRONT UPRIGHTS FOR A RACE CAR
}

\author{
Greg Wheatley $^{{ }^{*}}$, Caitlin Campbell ${ }^{2}$, Ben Moore $^{3}$ \\ Received in February $2020 \quad$ Revised in March $2020 \quad$ Accepted in April 2020 \\ RESEARCH ARTICLE
}

\begin{abstract}
Our contribution to fulfil the requirements for the mechanical design project was to audit the existing steering components and design an upright assembly for the JCU Motorsports FSAE car. We were required to assess the current status of the project and pick up where the previous team left off. As undergraduate engineers, we have followed the design process outlined in the assessment criteria issued at the commencement of the project. Many hours of work have been put into the design, material selection and loading analysis to come up with what we believe to be the best design given the constraints and timeline. A major guideline governing the design of the upright housing was the need for it to be reliable. This has been heavily factored into the design and is reflected in the analysis of the load cases giving significant room for errors in calculations and accounting for unforeseen circumstances which can cause significant angst for designers unfamiliar with the field. Overall the requirements of this project have been fulfilled to a high standard. We have taken what we have been given and produced a design to be incorporated into the motorsports project.
\end{abstract}

KEY WORDS: suspension, steering, design, finite element analysis

(C) 2020 Published by University of Kragujevac, Faculty of Engineering

\footnotetext{
${ }^{I}$ Greg Wheatley, PhD, Senior Lecturer, James Cook University, College of Science and Engineering, Townsville QLD 4811 Australia, greg.wheatley@jcu.edu.au (*Corresponding author)

${ }^{2}$ Caitlin Campbell, BE, James Cook University, College of Science and Engineering, Townsville QLD 4811 Australia, caitlin.campbell@my.jcu.edu.au

${ }^{3}$ Ben Moore, BE, James Cook University, College of Science and Engineering, Townsville QLD 4811 Australia, ben.moore@my.jcu.edu.au
} 


\section{O DIZAJNU UPRAVLJANJA I PREDNJIH NOSEĆIH ELEMENATA TRKAČKOG AUTOMOBILA}

REZIME: Naš doprinos ispunjenju zahteva mehaničkog dela projekta bio je revizija postojećih komponenti upravljanja i nosećih elemenata sklopa automobila JCU Motosports FSAE. Od nas se tražilo da procenimo trenutno stanje projekta i da utvrdimo gde je prethodni tim stao. Kao inženjeri osnovnih studija pratili smo proces projektovanja defisan u kriterijumima za ocenu koji su bili definisani na početku projekta. Mnogo sati rada je uloženo u analizu koncepta, izbor materijala i analizu opterećenja kako bi se došlo do onog za šta verujemo da je najbolje rešenje s obzirom na ograničenja i rokove. Glavna smernica u projektovanju nosača rukavca je bila njegova pouzdanost. Ovo je u velikoj meri implementirano u dizajn i ogleda se u analizi slučajeva opterećenja što daje značajan prostor za greške u proračunu i nepredvidjenim okolnostima koje mogu biti neprijatne za inženjere koji nisu stručni u ovoj oblasti. Sve u svemu, zahtevi ovog projekta su ispunjeni na visokom nivou. Uzeli smo ono što nam je bilo dato i napravili dizajn koji treba ugraditi u projekat moto sporta.

KLJUČNE REČI: oslanjanje, upravljanje, dizajn, analiza konačnim elementima 


\title{
ON THE DESIGN OF THE STEERING AND FRONT UPRIGHTS FOR A RACE CAR
}

\author{
Greg Wheatley, Caitlin Campbell, Ben Moore
}

\section{INTRODUCTION}

The aim of "Project B - Steering and Front Upright" is to design and build the steering system and front uprights for JCU Motorsports car. To help achieve this goal in the available time, various tasks were set. These include: Research the Formula SAE-A rules to determine restrictions and design requirements; Research on currently used automotive steering systems and evaluation of feasible alternatives; Analysis of previous year team's design; Design an appropriate steering system for the new race car; and Evaluate the performance of the steering system through programs in SolidWorks. The FSAE sports vehicle inter-university competition involves the design and construction of an on-road Open-Wheeler type sports vehicle dictated by FSAE rules and requirements. All James Cook University 3rd year Mechanical Engineering Project B team have the task to continue development of the Open-Wheeler sports vehicle; which was conceived by previous JCU Mechanical Engineering team. There has been little designed, documented or manufactured; and the car has not reached a test worthy phase. The previous team constructed a tubular steel frame, complete engine placement and mounts, seat mounts, a breaking reservoir template and both front and rear suspension [1] wishbones and a simple rack and pinion. Overall; this year's cohort hopes to finish designing most of the components and so that the car might be competing in the following year. Future expectations of the car include; high performance in terms of acceleration, braking and handling qualities as well as high reliability, low cost and easy maintenance. Following are the requirements that have an impact on the design process for steering and uprights. The vehicle is required to be an open-wheeled and open-cockpit design with four wheels not in a straight line. The steering must affect at least two wheels and the allowable free play is limited to 7 degrees total measuring from the steering wheel. The steering system must have positive stops to prevent steering linkages from locking up and to prevent the tires from contacting the car at all times. The allowable free play is limited to 7 degrees total, and is measured at the steering wheel. The Front Hoop must be no more than $250 \mathrm{mms}$ ( 9.8 inches) forward of the steering wheel and all parts near the driver's legs must be shielded with solid material for safety considerations. The steering wheel, steering column, seat and all padding may be removed during testing. Along with a quick disconnect of the steering wheel attached to the column. The driver must be able to operate the quick disconnect while in the normal driving position with gloves on.

\section{ANALYSIS}

During a high speed racing environment, various common load cases are placed on the vehicle upright assemblies. These load cases have been identified separately and then combined in order to simulate a 'worst case scenario' to obtain an accurate assessment of the loading capacity of the designed upright assembly. To achieve the most accurate analysis of the design, both static and fatigue loading cases have been applied to selected critical components. When available, the dimensions of the current vehicle have been measured in the workshop though due to the current stage of the project, the final mass of the car can only be estimated based on current measurements and designs put forth by other teams in the competition. The following values were used in calculating the load cases:

Mobility \& Vehicle Mechanics, Vol. 46, No. 1, (2020), pp 13-29 
Mass of Car

Centre of Mass

Wheelbase

Minimum turning radius

Coefficient of friction (rubber on asphalt)
$\mathrm{M}=350 \mathrm{~kg}$

$(\mathrm{x}, \mathrm{y}, \mathrm{z})=(931,279,197) \mathrm{mm}$

$1=1715 \mathrm{~mm}$

$\mathrm{r}=3512 \mathrm{~mm}$

$\mathrm{c}=0.8[2][3]$

Case one will find the forces on each of the uprights due to both acceleration and deceleration. Both conditions have been considered and it is expected that there will be greater force on the rear uprights during acceleration and greater force on the front uprights during deceleration. For this load case constant acceleration/deceleration has been assumed and an estimate made of the vehicle basic force analysis and moment analysis has been used to generate the following loads. From this the vertical forces on the front and rear uprights are:

$$
\begin{gathered}
F_{\text {front }}=\frac{1}{2} m g \frac{a_{2}}{l}-\frac{1}{2} m g \frac{h a}{l g} \\
F_{\text {rear }}=\frac{1}{2} m g \frac{a_{2}}{l}+\frac{1}{2} m g \frac{h a}{l g}
\end{gathered}
$$

From the current geometry of the previous FSAE car the dimensions are as follows;

$\mathrm{M}=350 \mathrm{Kg}, \mathrm{a}_{1}=851 \mathrm{~mm}, \mathrm{a}_{2}=864 \mathrm{~mm}, \mathrm{~h}=440 \mathrm{~mm}, \mathrm{~g}=9.81 \mathrm{~m} / \mathrm{s}^{2}, \mathrm{l}=1715 \mathrm{~mm}$ $\mathrm{a}=$ acceleration of car.

The acceleration of the car has been estimated at $0.9 \mathrm{~g}$, meaning the time taken to accelerate from standing to $100 \mathrm{~km} / \mathrm{h}$ would be approximately 3.1 seconds. This acceleration value has been obtained through research of other FSAE cars and represents an idealised performance of the JCU car.

$$
\begin{gathered}
a=0.9 g=8.829 \frac{\mathrm{m}}{\mathrm{s}^{2}} \\
F_{\text {front }}=\frac{1}{2}(350)(9.81) \frac{864}{1715}-\frac{1}{2}(350)(9.81) \frac{440 \times 8.829}{1715 \times 9.81}=468.48 \mathrm{~N} \\
F_{\text {rear }}=\frac{1}{2}(350)(9.81) \frac{851}{1715}+\frac{1}{2}(350)(9.81) \frac{440 \times 8.829}{1715 \times 9.81}=1248.27 \mathrm{~N}
\end{gathered}
$$

The results show that when the car is accelerating there is a higher vertical force on the rear upright than there is on the front upright. The deceleration of the car has been estimated at $1.3 \mathrm{~g}$, meaning the time taken to get the car to stop completely from a velocity of $100 \mathrm{~km} / \mathrm{h}$ would be just under 2.2 seconds. Again this is an idealised case though perhaps more realistic as the deceleration of the car depends heavily on the performance of the brakes and not power output of the engine.

$$
\begin{gathered}
a=1.3 g=12.753 \frac{\mathrm{m}}{\mathrm{s}^{2}} \\
F_{\text {front }}=\frac{1}{2}(350)(9.81) \frac{864}{1715}-\frac{1}{2}(350)(9.81) \frac{440 \times-12.753}{1715 \times 9.81}=1437.47 \mathrm{~N} \\
F_{\text {rear }}=\frac{1}{2}(350)(9.81) \frac{851}{1715}+\frac{1}{2}(350)(9.81) \frac{440 \times-12.753}{1715 \times 9.81}=279.29 \mathrm{~N}
\end{gathered}
$$


The results show that when the car is decelerating there are higher forces on the front upright than there is on the rear. This case refers to the roll of a vehicle when turning. It is very hard to model in a 3D dynamic situation however is easy to model at its extremes. When the car is turning, there is a tendency for the car move away from the centre of the turning radius known as centripetal forces. Because the wheels are constraining the car and the centre of mass is above the ground, will be inclined to roll. It can be assumed at an extremity that the FSAE car's inside wheels will apply a zero force to the track and potentially lift off the ground during a hard corner, subsequently the centripetal forces and also weight of the car will be acting through 2 uprights (outside front and rear). The vertical forces acting on the car at the point of wheel lift is as follows:

$$
\begin{gathered}
F_{\text {inner }}=\frac{1}{2} m g \\
F_{\text {outer }}=0
\end{gathered}
$$

Solving these equations given a car mass of $350 \mathrm{Kg}$ results in:

$$
\begin{gathered}
F_{\text {inner }}=1716.75 \mathrm{kN} \\
F_{\text {outer }}=0 \mathrm{~N}
\end{gathered}
$$

Because the car is in a rolling motion there is also a bending force on the inner front and rear uprights. This causes a moment on the hub shaft and the supporting bearings [4]. Because of the difference in upright geometry and bearings [5] in each upright the torsion force must be divided into two parts; one for the front upright and another for the rear.

The front upright hub shaft is supported by two bearings [6] $27 \mathrm{~mm}$ apart and $14 \mathrm{~mm}$ each wide. The $F_{\text {inner }}$ can be applied to the hub shaft bolts and resolved into two reaction forces contained on the upper and lower half at each bearing [7]. The followings equations were used to resolve the forces:

$$
\begin{aligned}
& \sum M_{\text {shaft }}=0 \\
& \sum F_{\text {shaft }}=0
\end{aligned}
$$

Where the sum of the moments about the shaft are equal to zero and the sum of the forces on the shaft is also equal to zero. The forces at each bearing [8] have been calculated as:

$$
\begin{aligned}
& \mathrm{F}\left(R_{b 1}\right)=2509.1 \mathrm{~N} \\
& \mathrm{~F}\left(R_{b 2}\right)=-792.3 \mathrm{~N}
\end{aligned}
$$

The brake calliper mounts on both the front and rear uprights are offset from the centre of rotation of the hub shaft. This means, when the car is braking, the upright in question will resist the braking force and thus experience torsion in slowing the car's velocity.

The force required to stop the car at a rate of $1.3 \mathrm{~g}$ :

$$
F=m a=350 \times(9.81 \times 1.3)=4464 \mathrm{~N}
$$

This force can then be converted into a torque using the radius of the wheel:

$$
T_{t}=F \cdot r_{w}
$$




$$
T_{t}=4464 \times 0.25=1116 \mathrm{Nm}
$$

This is the torque required to stop the car, this torque will be distributed between the four uprights of the car. The FSAE rules state that the front brakes must be able to apply a force capable of stopping $100 \%$ of the car, and the rear brakes must be able to stop $60 \%$ of the car. The front uprights must then be able to resist a torque of:

$$
\begin{gathered}
T_{t}=1116 \mathrm{Nm} \\
T_{f w}=558 \mathrm{Nm} \rightarrow \text { force per front wheel }
\end{gathered}
$$

The torque on each the wheel can then be resolved into a force acting at brake calliper bolt holes in a direction which is tangent to the pitch circle diameter:

$$
\begin{gathered}
F_{P C D}=T_{f w} x r_{P C D} \\
F_{P C D}=558 \times 0.092=51.336 \mathrm{~N}(\text { Caliper Holes Total })
\end{gathered}
$$

Two bolts keep the calliper in position. It is assumed that the force is distributed equally between them resulting in a force per hole of $\mathrm{F}_{\text {hole }}=25.7 \mathrm{~N}$. Intuitively, the force on the rear upright mounts is $60 \%$ of this assuming a common pitch circle diameter. Another force common to racing is that of hitting a bump at high speed which is prone to any of the wheels of the car. Unlike the other cases it is very hard to quantify the amount of force on the uprights when the car hits a bump in the road. In some instances this case can be disregarded under the assumption that the FSAE car is designed for on road use, where bumps are uncommon and can be neglected. However, due mainly to the fact that the JCU FSAE motorsports team is still in the early stages of designing a car and has very limited prior experience the case will be included to account once again for a 'worst case scenario'. FSAE forums and other literature suggest that the force on the upright due to a bump in the road is three times the mass of the car. The bump force equation has been generated assuming that the cars weight is distributed evenly by the four uprights due to lack of knowledge on the mass distribution of the finished car and the force distribution at the time of the bump. The current calculation for the centre of mass dictates that there will be $156 \mathrm{~kg}$ supported by the front two wheels meaning that this assumption is not a conservative underestimate of this weight.

$$
\begin{gathered}
F_{\text {front }}=3 m g=3 \times \frac{350}{4} \times 9.81=2675.125 \mathrm{~N} \\
F\left(R_{b 1}\right)=5048 \mathrm{~N} \\
F\left(R_{b 2}\right)=-2423 \mathrm{~N}
\end{gathered}
$$

When taking into account cornering forces we look back into basic system dynamics [9]. If a car is taking a corner as fast as it possibly can, then the friction force will be the same as the normal force, which is the basis of the calculation. When the car begins to slip the forces on the upright will decrease, therefore the critical point when the forces are highest on the upright is the point just before slipping occurs. Thus when the traction force is equal to the normal component of force, there is the highest amount of force on the uprights. The diagram below shows how the normal component of force is calculated.

$$
F_{\text {traction }}=F_{\text {normal }}
$$




$$
\begin{gathered}
c m g=m a_{n} \\
c g=a_{n} \\
a_{n}=7.848 \frac{m}{s^{2}}
\end{gathered}
$$

We also know that the acceleration in the normal direction can be resolved into an angular velocity:

$$
\begin{gathered}
a_{n}=\omega^{2} r \\
\omega=1.5 \frac{\mathrm{rad}}{\mathrm{s}} \\
V=\omega r=1.5 \times 3.5=5.241 \frac{\mathrm{m}}{\mathrm{s}} \approx 20 \frac{\mathrm{km}}{\mathrm{h}} \\
\left|F_{r}\right|=\frac{1}{2} m \frac{\mathrm{V}^{2}}{\mathrm{r}} \\
\left|F_{r}\right|=\frac{1}{2}(350) \frac{(5.241)^{2}}{3.5}=1373.4 \mathrm{~N}
\end{gathered}
$$

This is the theoretical force exerted on the uprights due to cornering. Though the case is highly simplified, it provides an estimate of the forces during cornering without the use of complex 3D modelling. A total of 5 individual loading conditions on the upright assembly have been identified. Of these, two combined loading case scenarios will be used for analysis to achieve an extreme loading condition for each of critical parts of the assembly. The upright housing and hub shaft will have two load cases applied and will be analysed in both static and fatigue conditions to ensure longevity. The first set of load cases takes into consideration a regular combination on the racing track whereby the vehicle is entering a corner at high velocity and so the driver is slowing down at maximum deceleration into a corner. In this case, there is torsion on the upright housing due to the brake callipers, a high deceleration force on the front uprights and also a cornering force. The second load case of a bump was applied to both the upright housing and the hub shaft. Though practically an uncommon occurrence on a smooth racing track, they were taken into account to ensure the upright design components can withstand the forces. The load case applied to the steering anchor was half of the force due to cornering, as there are two wishbone supports, as well as the maximum force calculated for steering in the direction of the steering arm. For this component only a heavy corner would apply the maximum loading conditions which have been considered. Loading on the bearing [10] cap was taken to be the full force of the cornering load in the event that there is catastrophic failure of the bearings [11] and the entire load is applied to the cap which would essentially be holding the hub shaft in the bore of the main housing. It is important that this component be strong enough to withstand these forces as it could prevent the wheel detaching from the car in the event of a crash. As with the bearing [12] cap, the shaft retainer was also assessed under the full load assuming catastrophic bearing failure. Two sets of loading cases were applied to the upright housing. 


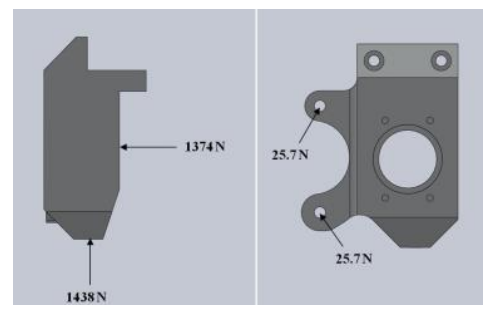

Figure 1. Deceleration, Braking and Cornering load case on upright housing

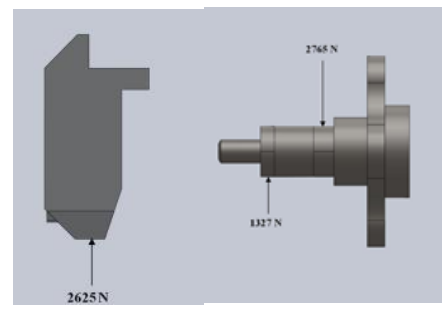

Figure 2. Bump load case on upright housing (L) Deceleration, Braking and Cornering load case on hub shaft $(\mathrm{R})$

For each load case applied to the upright housing, the magnitude and direction of the forces is indicated in the figures 1 and 2. The brake calliper forces were applied to the holes at a direction tangent to the pitch circle diameter and the other forces applied to the circular bore where the bearings would contact both normal and parallel to the surface. The fixture was added to the holes at the bottom wishbone support bolt hole and the holes at the top where the steering anchor bolts to the upright housing.

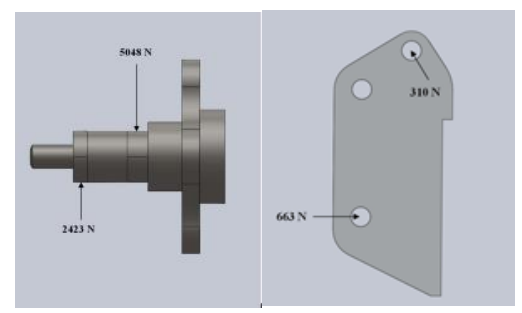

Figure 3. Bump load case on hub shaft (L) Deceleration, Braking and Cornering load case on steering anchor $(\mathrm{R})$

The loads on the hub shaft have been applied at the upper and lower halves of the shaft where the bearings make contact. The bearings are self-aligning and can thus allow for any curvature in the shaft due to moments. The fixtures were added to the bolt holes where the wheel would bolt on to allow for accurate simulation of how the bearings would behave under loading thus not restricting completely the bending motion of the shaft. The forces on the steering anchor were applied to the top wishbone contact point and the steering arm bolt hole. The restraints for the anchor were the holes which are used to bolt to the upright housing. 


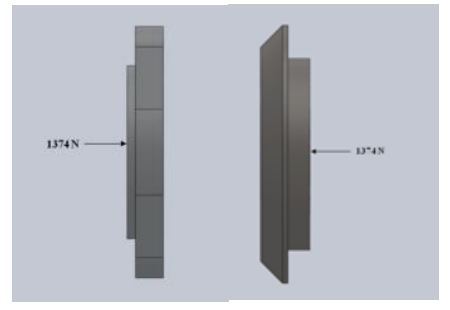

Figure 4. Deceleration, Braking and Cornering load case on bearing cap (L) Deceleration, Braking and Cornering load case on shaft retainer $(\mathrm{R})$

The bearing cap loading was applied to the face where the bearings could push on the face. The restraints where positioned at the holes holding the cap to the upright housing. The force applied to the shaft retainer was at the contact point with the bearing inner race. The restraint for the shaft retainer was located on the opposite side at a circle approximately equal to the size of the bolt head holding the retainer to the hub shaft. Selection and placement of the upright hub/shaft bearings requires calculations to determine selection is correct and bearings are capable of withstanding maximum forces applied during a racing event. Maximum forces applied to the RHF upright include a combination of loads during a race [13] event such as heavy cornering to the left, hard braking and a 'bump' impact. Analysis on the forces inflicting the RHF upright hub/shaft are depicted in figure 3 and illustrate the loads applied at particular locations. The force applied to the right-hand angular contact bearing supports the highest load and is therefore the point of interest for analysis. NTN supplies formulas and loads allowable to determine the actual loads applied to the bearing. The formula incorporates a load factor fw and is obtained by bearing manufacture Data Sheets as per Appendix 00. The maximum permissible dynamic load applied to the bearing is $17500 \mathrm{~N}$. Calculating the Actual Load to bearing is fw $\mathrm{x}$ Applied Load $=$ Actual Load, 1.5 x 4795N $=7192.5$ N . Therefore, Factor of Safety for NTN 7007 Angular Contact Bearing is

$$
F_{o} S=\frac{17500}{7192.5}=2.43
$$

Referencing the textbook 'Applied Mechanical Design', 1986 regarding Factor of Safety of 2 is recommended for general basic endurance applications. The NTN 7007 Angular Contact bearing is recommended and safe for use within the FSAE Sports Vehicle front upright housings. Performing an analysis on the designed hub/shaft with a current diameter of $35 \mathrm{~mm}$, at bearing locations, it is assumed the location enduring the highest stress concentration will be at the step in shaft diameter on the right bearing. Complying with AS1403-2004 'Design of Rotating Steel Shafts', formula 33 has been selected due to the required criteria. The formula is:

$$
D_{3}=\frac{10^{4} \cdot F_{S}}{F_{r}} \sqrt{\left[K_{S} \cdot K \cdot\left(M_{q}+\frac{P_{q} \cdot D}{8000}\right)\right]+\frac{3}{4} T_{q}{ }^{2}}
$$

Subbing values for all the variables include:

$F_{S}=2\left(F_{o} \mathrm{~S}\right) ;$ factor of safety

$M_{q}=2600 \mathrm{~N} \cdot 0.038 \mathrm{~m}=98.8 \mathrm{Nm}$ Movement at the investigated point

$K_{s}=1.325 ;$ Surface

Mobility \& Vehicle Mechanics, Vol. 46, No. 1, (2020), pp 13-29 
$\mathrm{K}=\mathrm{K} 4+\mathrm{K} 6=1.9+2.7=4.6$; the summation of aspect ratio (shafts)

$P_{q}=0$; normal

$T_{q}=0 ;$ torque

$F_{r}=\mathrm{Sn}^{\prime} \cdot \mathrm{CL} \cdot \mathrm{CG} \cdot \mathrm{CS} \cdot \mathrm{CT} \cdot \mathrm{CR}=0.5 \cdot 1020 \cdot 1 \cdot 0.9 \cdot 0.8 \cdot 1 \cdot 0.753=276 \mathrm{MPa}($ Fatigue or endurance limit).

$\mathrm{D}=26 \mathrm{~mm}$ minimum required. Current shaft diameter is $35 \mathrm{~mm}$ which is safe for use as per AS1403-2004.

Manual fatigue analysis was undertaken on the upright housing and the hub shaft. The following equation was used in order to obtain a figure for the safety factor:

$$
\frac{\sigma_{a}}{S_{f n}}+\frac{\sigma_{m}}{S_{u t}}<\frac{1}{N}
$$

Where

S $f n=$ Fatigue Strength (Endurance Limit)

Sut $=$ Ultimate Tensile Strength

$\mathrm{N}=$ Safety Factor

Table 1. Endurance calculations for the hub shaft and upright housing materials

\begin{tabular}{|c|c|c|c|}
\hline \multicolumn{1}{|c|}{ Factor } & & $\begin{array}{c}\text { Hub Shaft AISI } \\
4140 \mathrm{CS}\end{array}$ & $\begin{array}{c}\text { Upright Housing } \\
\text { 2024 T3 Al Alloy }\end{array}$ \\
\hline Ultimate Tensile Strength (MPa) & $\mathrm{S}_{\mathrm{u}}$ & 1140 & 428 \\
\hline R.R. Moore Endurance Limit (MPa) & $\mathrm{S}_{\mathrm{e}}{ }^{\prime}$ & 570 & 171.2 \\
\hline Load Factor & $\mathrm{C}_{\mathrm{L}}$ & 1 & - \\
\hline Gradient Factor & $\mathrm{C}_{\mathrm{G}}$ & 0.9 & - \\
\hline Surface Factor & $\mathrm{C}_{\mathrm{S}}$ & 0.8 & - \\
\hline Temperature Factor & $\mathrm{C}_{\mathrm{T}}$ & 1 & - \\
\hline Reliability & $\mathrm{C}_{\mathrm{R}}$ & 0.753 & 138 \\
\hline Endurance Limit (MPa) & $\mathrm{S}_{f n}$ & 309 & - \\
\hline
\end{tabular}

Table 2. Estimated safety factors for fatigue of the hub shaft and upright housing materials

\begin{tabular}{|c|c|c|c|}
\hline \multicolumn{2}{|c|}{ Factor } & $\begin{array}{c}\text { Hub Shaft AISI 4140 } \\
\text { CS }\end{array}$ & $\begin{array}{c}\text { Upright Housing } \\
\text { 2024 T3 Al Alloy }\end{array}$ \\
\hline Mean Stress & $\sigma_{\mathrm{a}}$ & 0 (Fully Reversed) & 0 (Fully Reversed) \\
\hline Stress Amplitude & $\sigma_{\mathrm{m}}$ & 5048 & 1438 \\
\hline Fatigue Strength & $\sigma_{\mathrm{fn}}$ & 309000000 & 138000000 \\
\hline Ultimate Tensile Strength & out & 1140000000 & 428000000 \\
\hline
\end{tabular}




\begin{tabular}{|c|c|c|c|}
\hline Safety Factor & $1 / \mathrm{N}$ & $1.63366 \mathrm{E}-05$ & $1.04203 \mathrm{E}-05$ \\
\hline Maximum Safety Factor & $\mathrm{N}$ & 61212.36133 & 95966.62031 \\
\hline
\end{tabular}

For each of the materials, the safety factor has been calculated using the formula. Each of the metals is clearly strong enough to withstand the required loading effects applied to the upright assembly even though unrealistic fatigue cases have been applied to each. The hub shaft has been assessed at a bump force fatigue loading fully reversed and the upright housing has been assessed for normal expected deceleration, braking and cornering load case also fully reversed.

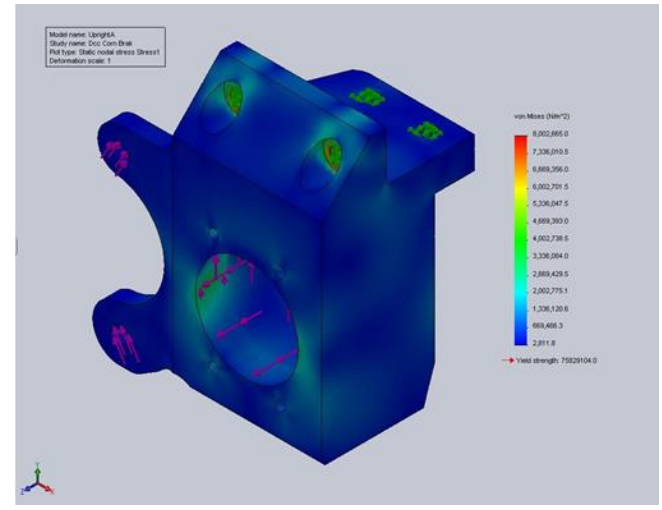

Figure 5. FEA Deceleration, Braking and Cornering load case on upright housing - Max Stress: $8 \mathrm{MPa}$, 75.8 Yield Stress: MPa, Safety Factor: 9.5
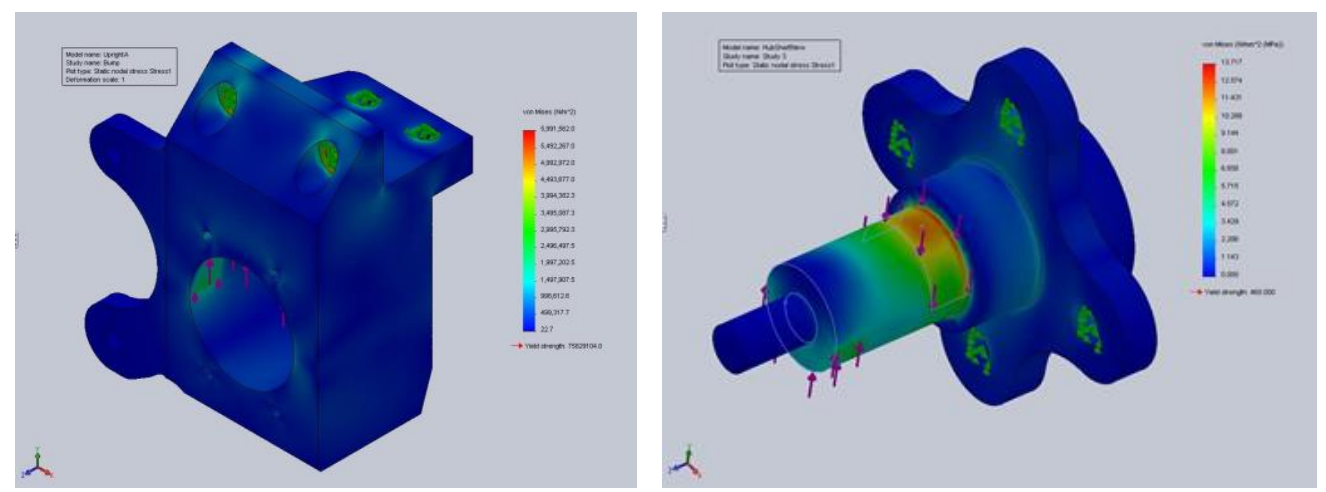

Figure 6. FEA bump load case on upright housing - 5.99 Max Stress: MPa 75.8 Yield Stress: MPa, Safety Factor: 12.65 (L) FEA Deceleration, Braking and Cornering load case on upright housing - Max Stress: 13.7 MPa, Yield Stress: $460 \mathrm{MPa}$, Safety Factor: 33.6 (R) 

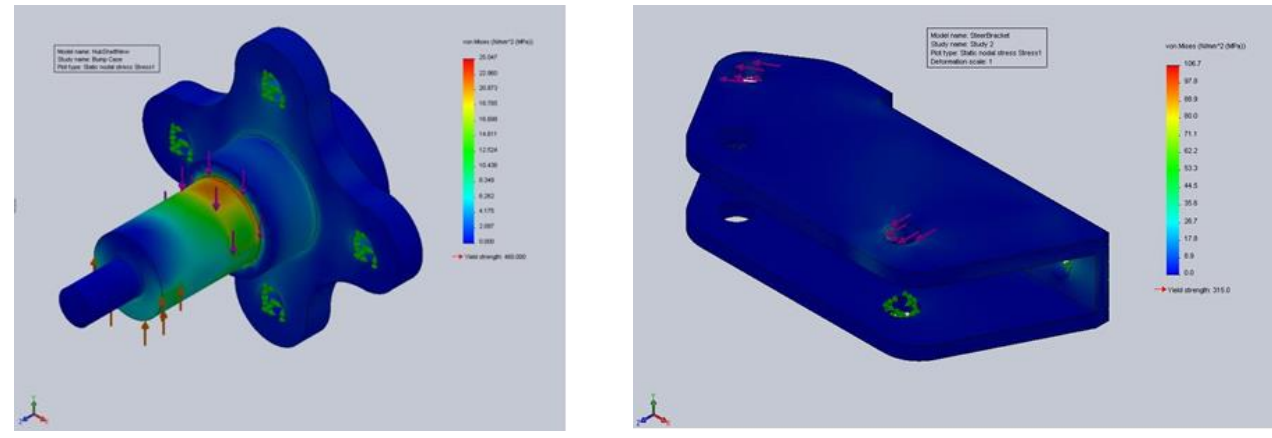

Figure 7. FEA bump load case on upright housing - Max Stress: 25 MPa, Yield Stress: 460 MPa, Safety Factor: 18.4 (L) FEA cornering and steering load case on upright housing Max Stress: 106.7 MPa, Yield Stress: 315 MPa, Safety Factor: 2.95 (R)
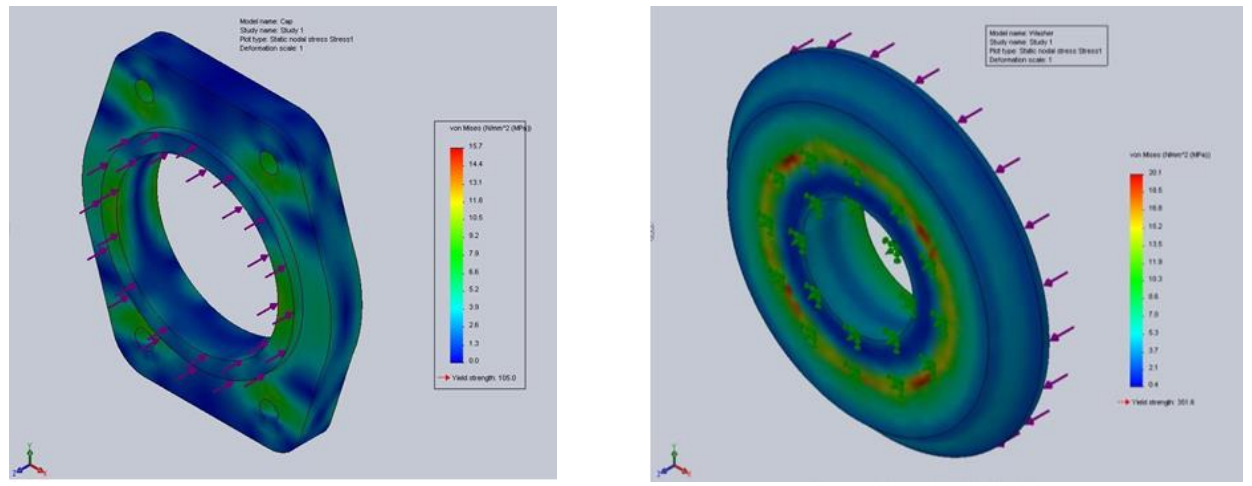

Figure 8. FEA cornering load case on upright housing - Max Stress: 15.7 MPa, Yield Stress: $105 \mathrm{MPa}$, Safety Factor: 6.7 (L) FEA cornering load case on upright housing - Max Stress: 20.1 MPa, Yield Stress: 351.6 MPa, Safety Factor: 17.5 (R)
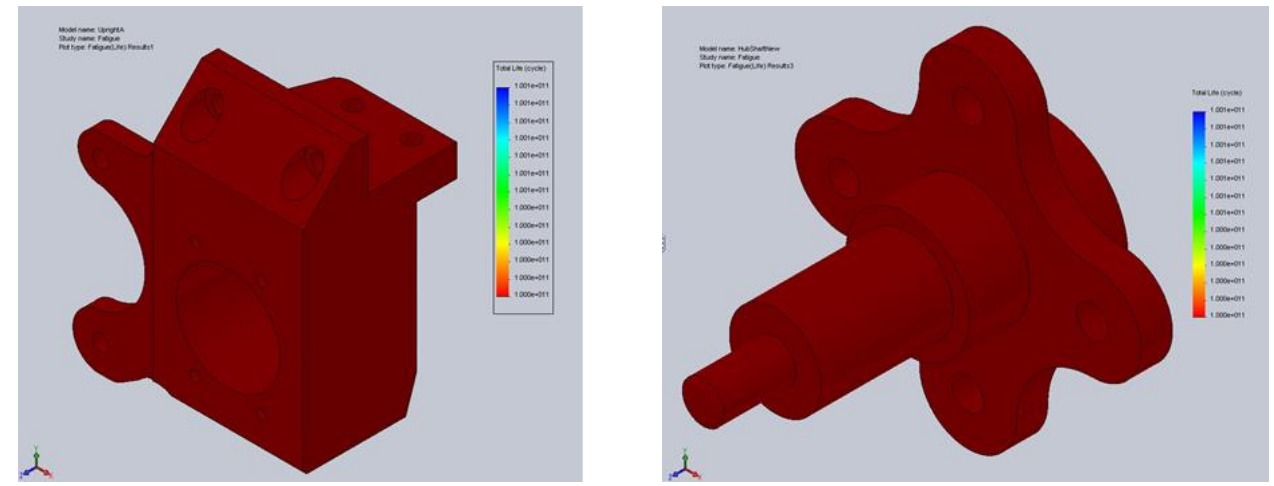

Figure 9. FEA Deceleration, Braking and Cornering fatigue load case on upright housing for infinite life (L) FEA Deceleration, Braking and Cornering fatigue load case on hub shaft for infinite life (R) 
Using Eulers formula adapted to a cylinder you attain:

$$
P_{c r}=\frac{\pi^{2} \cdot E \cdot I}{L e^{2}}
$$

Where I is the inertia $=\frac{\pi \cdot d^{2}}{64}$; and Youngs modulus is $690 \mathrm{GPa}$. The $L_{e}=180 \mathrm{~mm}, P_{c r}=$ $288725 \mathrm{~N}$. Therefore the amount of force that the Aluminium protectors can handle is $288.725 \mathrm{kN}$ which is over the amount of force being applied from the tyres. Due to the steering system being made of material higher than the given critical force; the steering system won't be considered for a full static analysis and will only incorporate changes in the steering arm components or rack protector. The different components of the assembly will be applied forces such as axial forces i.e. tensile and compressive force and also shear forces. The force acting on the assembly is cornering force which is being calculated $660 \mathrm{~N}$.

The finite element analysis of the components is done using Solidworks simulation and the results are shown below. The connecting arm will be mainly applied to axial forces i.e. tensile and compressive force. The yield strength of the material used for the connecting arm is $220 \mathrm{MPa}$. The Solidworks force analysis simulation done on this part is shown in the figure below.

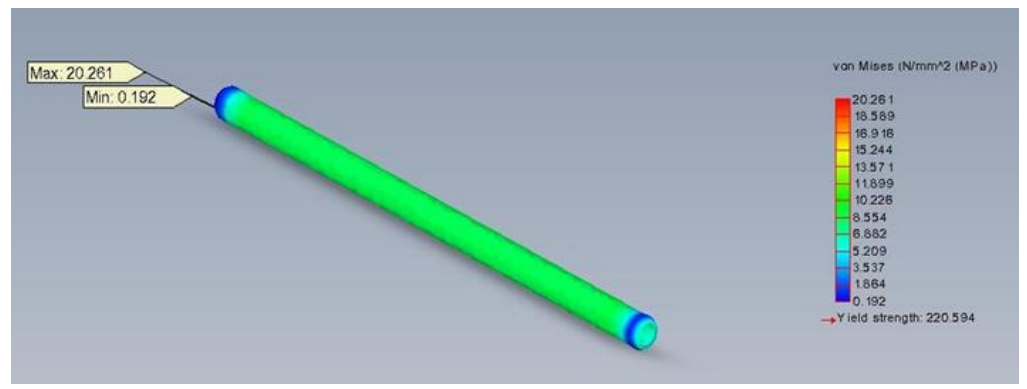

Figure 10. Connecting rod in tension

The simulation shows that the minimum FOS for this design is 10. And the maximum stress produced in the rod is $20 \mathrm{MPa}$ which is much lower than allowable stress so the design is safe. The tie rod is also applied to axial forces. The critical forces acting on the tie rod is at threads. The shear force at the thread face, the tension at the bottom of the thread. And also the crushing at the top of the threads. The Solidworks simulation done on the tie road is shown below.
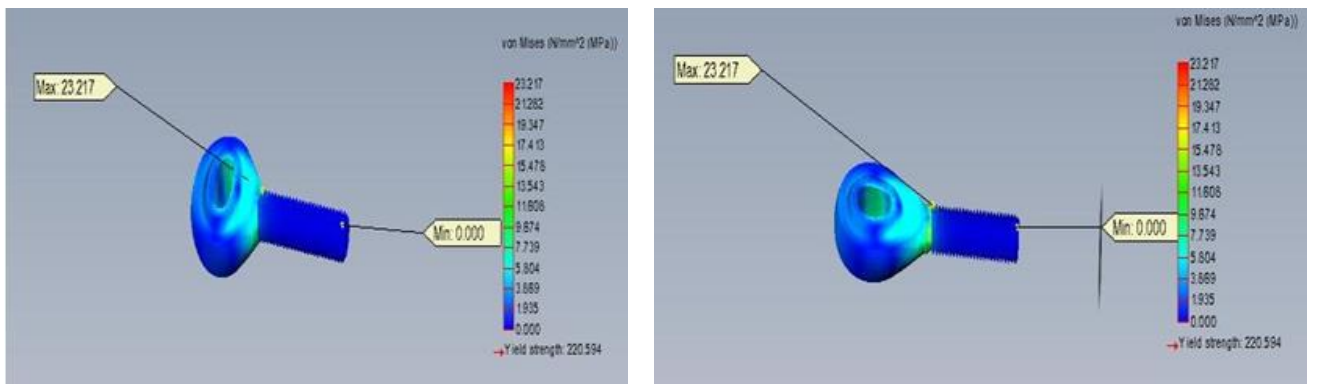

Figure 11. Tie rod in compression (L) Tie rod in tension (R) 
We can observe from the simulation that the maximum stress produced during axial loading on the tie rod end is $23.217 \mathrm{MPa}$ and the minimum FOS for the component we used is 9.5. Clevis will be applied to axial force as well. During compression the force will act on the face of the clevis by the extension rod and during tension the force will be applied to the clevis by the hexagonal cap screw. The simulation of the force analysis using Solidworks is shown below.
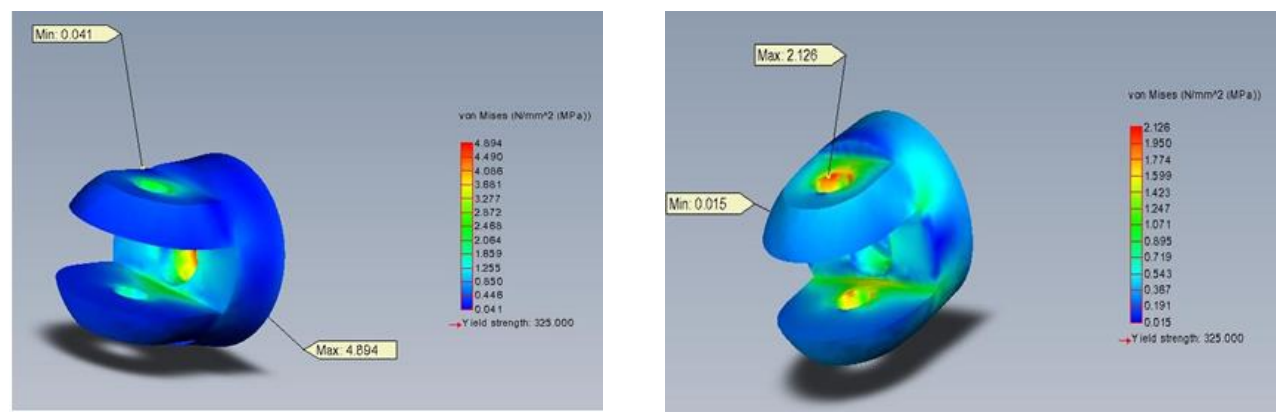

Figure 12. Clevis under axial loading

The simulation shows that the minimum FOS of the component while applied load is 66 . And the maximum stress produced is $4.89 \mathrm{KPa}$. This screw will also subject to axial loading. The simulation data is shown below. The screw will be subjected to tensile force only.

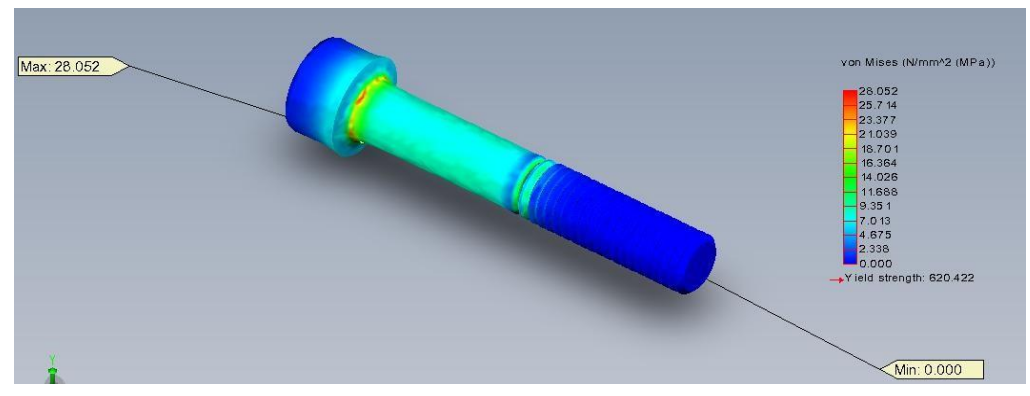

Figure 13. Hexagonal socket head cap screw applied to tensile load

From the simulation we can see that the maximum stress induced in the part will be 28.05 $\mathrm{MPa}$ and the minimum FOS is 22 for the used screw. There are two bolts used in the assembly one is to connect clevis to the connection arm and the other is to connect the upright to the arm. At both the places the screw will be applied to the double shear. The shear force induced in the hexagonal bolt is,

$$
\tau=\frac{P}{2 A}=\frac{660}{\frac{\pi}{4}(0.0095)^{2}}=4.65 \mathrm{MPa}
$$

Analytically the minimum FOS is 137 . So the hexagonal bolt we used is also safe in double shear. When observing the rack protector on the previous design; the load being translated through the protectors would be concentrated at the end of the shaft. Applying the load of $660 \mathrm{~N}$ to the ends of the shaft and observing the safety factor and deformation of the shaft. 


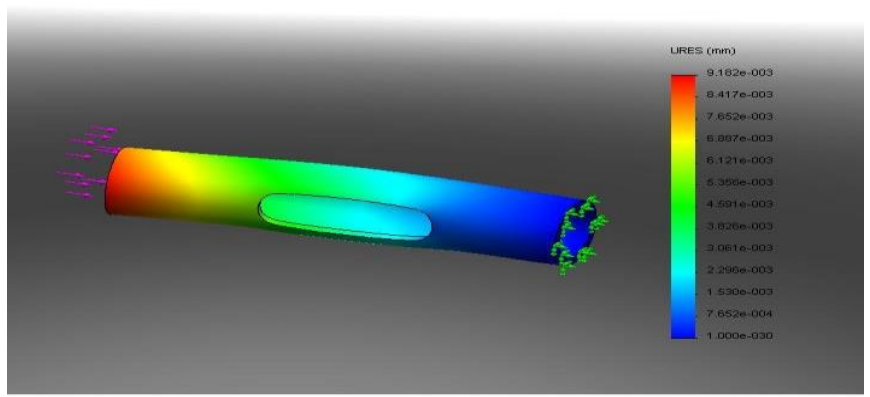

Figure 14. Deformation on the shaft

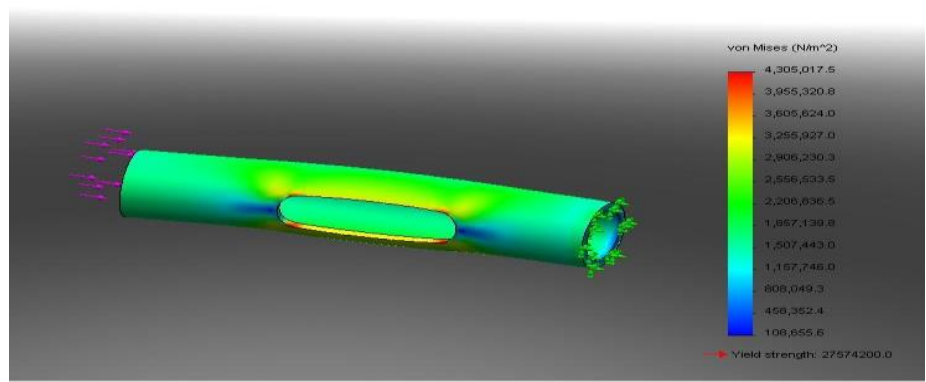

Figure 15. Von Misses Stress on the shaft

As it can be seen in the FEA results; the shaft attains minimal deformation and a common stress of $1.15 \mathrm{MPa}$ throughout the shaft. When comparing the stress against the yield strength $27.5 \mathrm{MPa}$ for aluminium; it can be seen that the shafts stress is less. However to make sure the design is able to withstand repeated loading and infinite the life; the shaft is modified with a thicker diameter at the ends. This is checked against with FEA simulation and the changes in the stresses and deformation are observed.

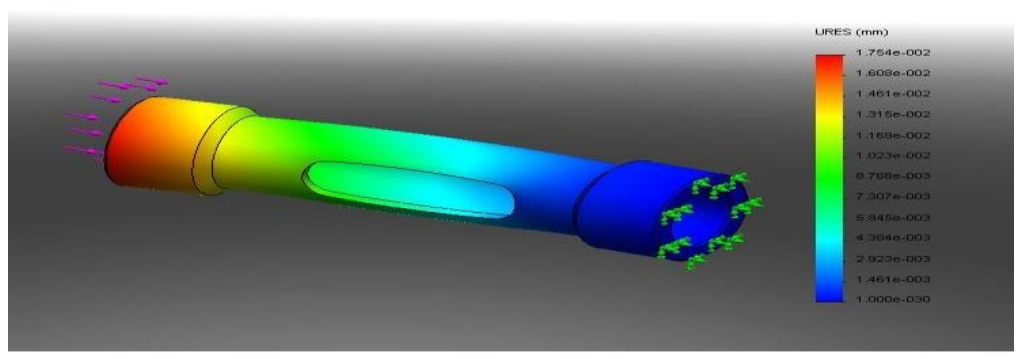

Figure 16. Deformation on the modified shaft 


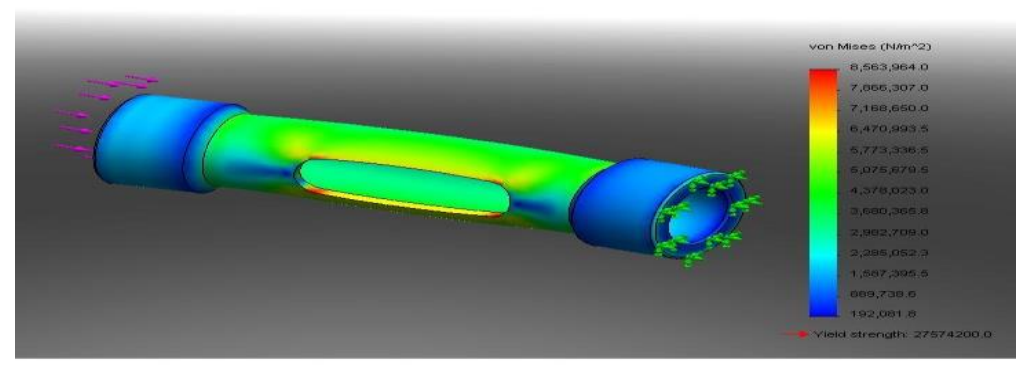

Figure 17. Von Misses Stress on the shaft

Even though the modified shaft has increased the stresses recorded in the middle of the shaft; it has minimized the deformation and has created stable ends which are constantly impacted on throughout the design's life.

\section{CONCLUSION}

Our contribution to fulfil the requirements for the mechanical design project was to audit the existing steering components and design an upright assembly for the JCU Motorsports FSAE car. We were required to assess the current status of the project and pick up where the previous team left off. As undergraduate engineers, we have followed the design process outlined in the assessment criteria issued at the commencement of the project. Many hours of work have been put into the design, material selection and loading analysis to come up with what we believe to be the best design given the constraints and timeline. A major guideline governing the design of the upright housing was the need for it to be reliable. This has been heavily factored into the design and is reflected in the analysis of the load cases giving significant room for errors in calculations and accounting for unforeseen circumstances which can cause significant angst for designers unfamiliar with the field. Overall the requirements of this project have been fulfilled to a high standard. We have taken what we have been given and produced a design to be incorporated into the motorsports project.

\section{REFERENCES}

[1] Allan S.: 'Competition Car Suspension', 2006.

[1] Machinerys HandBook, 27th Edition, 2007.

[2] http://www.engineershandbook.com/Tables/frictioncoefficients.htm.

[3] http://www.skf.com/skf/productcatalogue/jsp/viewers/imageViewerJs.jsp?image=b earingselection.jpg\&file=1_0_2\&maincatalogue=1\&lang=en .

[4] http://www.skf.com/portal/skf/home/products?maincatalogue=1\&lang=en\&newlin $\mathrm{k}=1 \_3 \_13$.

[5] http://www.skf.com/portal/skf/home/products?maincatalogue=1\&lang=en\&newlin $\mathrm{k}=1 \_3 \_4$.

[6] http://www.skf.com/skf/productcatalogue/jsp/viewers/productTableViewer.jsp?tabl eName=1_3_1\&maincatalogue=1\&lang=en.

[7] http://www.skf.com/skf/productcatalogue/Forwarder?action=PPP\&lang=en\&imperi $\mathrm{al}=$ false $\&$ window Name=null $\&$ perfid $=123006 \&$ prodid $=1230060307$. 
[8] http://www.skf.com/portal/skf/home/products?maincatalogue=1\&lang=en\&newlin $\mathrm{k}=1 \_3 \_25$.

[9] Thomas, D. Gillespie: 'Fundamentals of Vehicle Dynamics', 1992.

[10] http://www.skf.com/skf/productcatalogue/Forwarder?action=PPP\&lang=en\&imperi $\mathrm{al}=$ false $\&$ window $\mathrm{Name}=$ null $\&$ perfid $=125010 \&$ prodid $=125010407$.

[11] http://www.nsk.com/products/ballbearing/angularcontact/pdf/NSK_CAT_E1102h_B 46-B75.pdf.

[12] http://www.tec.nsk.com/Handbook.asp?menu=7,0,0,0\&PageID=/FitsAndInternalCle arances/RadialBearingAndHousingBores.html.

[13] http://www.tec.nsk.com/Handbook.asp?menu=7,0,0,0\&PageID=/FitsAndInternalCle arances/RadialBearingsAndShafts.html.

[14] http://www.revolutionracegear.com.au/index.php?PCID=10546\&PSO=245\&PSID=63 $5661 \& \mathrm{PSV}=$ Primary \&CDO. 